\title{
Long-term safety and efficacy of infliximab for the treatment of ankylosing spondylitis
}

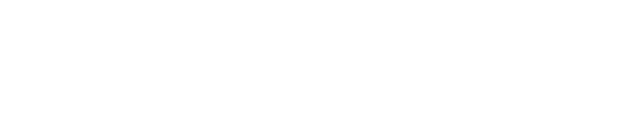

\section{Ofir Elalouf \\ Ori Elkayam}

Department of Rheumatology, Sackler Faculty of Medicine, Tel Aviv Medical Center, Tel Aviv, Israel
Correspondence: Ori Elkayam

Department of Rheumatology, Tel Aviv Medical Center, 6 Weizmann Street,

Tel Aviv 6423906, Israel

Tel+97236973243

Email oribel4@netvision.net.il
Abstract: The introduction of TNF $\alpha$ blockers has revolutionized the treatment of ankylosing spondylitis (AS). The objectives of this review are to summarize the most up-to-date data on long-term efficacy and safety of infliximab in AS, with special emphasis on axial and extraarticular disease, predictors of response, and radiological response. The general consensus of this literature search was that infliximab is highly efficacious in the treatment of AS. Most studies have demonstrated good clinical outcomes after 3 years of treatment, as measured by Spondyloarthritis International Society response in $75 \%-85 \%$ of treated AS patients. Reports on the long-term effects of infliximab as documented by radiological findings, however, are controversial. While some studies reported a similar progression rate as that of the historical OASIS cohort, others have suggested that infliximab may halt new bone formation. The longterm safety of infliximab is well known, mainly from data stored in national registries. While it has been suggested that side effects of infliximab may be fewer in AS compared to rheumatoid arthritis, data on this issue are sparse, with most of the information on long-term safety pertaining to rheumatoid arthritis. It can however be concluded that the long-term efficacy of infliximab is apparently maintained in AS and with an acceptable safety profile.

Keywords: spondylitis, long-term efficacy, safety, TNF $\alpha$ blockers

\section{Introduction}

Ankylosing spondylitis (AS) is a chronic inflammatory disease primarily affecting the axial skeleton, including the sacroiliac joints and the spine. It is more common in young men, with a prevalence of $0.15 \%-0.8 \%$ in the general population. ${ }^{1}$ The main symptoms are inflammatory low-back pain, which is characterized by rest pain, especially at night and early morning and accompanied by morning stiffness. Extra-axial involvement can also be present, and includes peripheral arthritis (most commonly asymmetrically oligoarthritis of large joints), enthesitis, and dactylitis., ${ }^{2,3}$ Extra-articular involvement is not uncommon, and includes anterior uveitis, inflammatory bowel disease, psoriasis, and others. ${ }^{4-6}$

Managing patients with AS consists of patient education, exercise, lifestyle modifications, and medications. ${ }^{7}$ In addition to the aid provided by the clinician, patient education and support can be obtained from support groups. Smoking is correlated with poor functional outcome, and it is one example of a modifiable risk factor. ${ }^{8}$

Nonsteroidal anti-inflammatory drugs are usually the first-line therapy and the only medication required by many patients. Approximately $70 \%-80 \%$ of AS patients report a substantial relief of the back pain and stiffness compared to $10 \%-15 \%$ of patients with mechanical back pain. ${ }^{9}$ In contrast, synthetic disease-modifying antirheumatic drugs (DMARDs), such as methotrexate, sulfasalazine, and corticosteroids, have failed to demonstrate a significant role in the treatment of axial disease, ${ }^{10-12}$ and are usually not recommended. 
The introduction of anti-TNF $\alpha$ agents in 2000 represented a major advance in the treatment of AS. Early trials with infliximab and later on with other anti-TNF $\alpha$ agents demonstrated significant improvement in the clinical measures. ${ }^{13,14}$ Anti-TNF $\alpha$ agents are also indicated in patients with active disease who are already being treated with nonsteroidal antiinflammatory drugs. Currently, the five anti-TNF $\alpha$ agents available in the USA and Europe for AS are infliximab, etanercept, adalimumab, golimumab, and certolizumab pegol. The aim of this review was to assess the long-term safety and efficacy of infliximab for the treatment of AS.

\section{Efficacy and clinical response}

\section{Axial disease}

Infliximab, the first anti-TNF $\alpha$ agent introduced for the treatment of AS, usually induces rapid remission and decreases disease activity. ${ }^{14,15}$ Extra-articular manifestations of the disease also tend to respond to anti-TNF $\alpha$ therapy. ${ }^{16}$ The first randomized controlled trial that demonstrated the efficacy of infliximab in AS was by Braun et al. ${ }^{17}$ They randomized 69 patients with active AS to receive infliximab $5 \mathrm{mg} / \mathrm{kg}$ or placebo. After 12 weeks of treatment, $53 \%$ of the patients in the treatment group vs only $9 \%$ of the patients in the placebo group reported significantly decreased disease activity (as measured by a $50 \%$ reduction in the Bath Ankylosing Spondylitis Disease Activity Index [BASDAI]) (Figure 1). Physical function and quality of life (as measured by the Bath Ankylosing Spondylitis Functional Index and Short-Form 36 Health Survey, respectively) significantly improved as well $(P<0.0001)$. That first 12-week placebo-controlled trial was followed by a 3 -year open-label extension that was completed by 43 of the 69 patients $(62 \%)$. According to the study protocol, infliximab was discontinued after 3 years in order to evaluate time to flare. Most of the patients relapsed within 18-24 weeks, and 42 of them were restarted

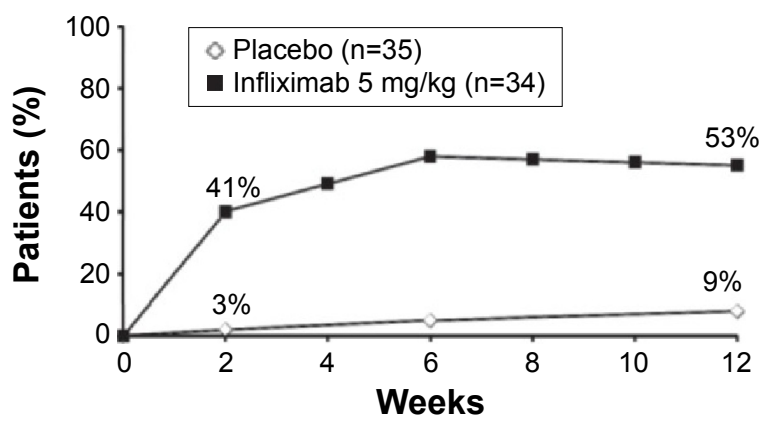

Figure I Ankylosing spondylitis: disease activity.

Notes: Infliximab rapidly reduced disease activity compared with placebo ( $n=70$ patients). Percentage of patients with improvement of $50 \%$ in the Bath Ankylosing Spondylitis Disease Activity Index. $P<0.000$ I from 2 weeks onward. on infliximab, with a good response for most. Good clinical response (BASDAI $<50 \%$ ) was sustained for approximately $60 \%$ of the patients for 5 years (Figure 2 ).${ }^{18}$ Other measures that were carried out in the extended trial and also showed promising results included Assessment of the Spondyloarthritis International Society (ASAS) 40 response, which was reached in $75 \%$ and $63 \%$ of patients at the end of 3 and 5 years, respectively. Similarly, an ASAS 5/6 response was achieved in $76 \%$ and $71 \%$ of patients at the end of 3 and 5 years, respectively. A BASDAI score $<3$ units (low disease activity) was attained in $57.9 \%$ of patients after 5 years. Those authors concluded that the high relapse rate and the short period to flare after discontinuation of the drug suggested that continuous therapy is necessary in patients with severe active AS.

The ASSERT trial compared infliximab $5 \mathrm{mg} / \mathrm{kg}$ vs placebo in 279 AS patients. ${ }^{19}$ In that randomized controlled trial, the clinical response was rapid and good activity scores were recorded, with values that were comparable to Braun et al (Figure 3). ${ }^{16}$ The European Ankylosing Spondylitis Infliximab Cohort (EASIC), a European multicenter study of long-term outcomes in patients with AS who were treated with infliximab, is an open-label continuous study based on the ASSERT trial patients. ${ }^{20}$ Patients from the ASSERT trial continued into an open-label phase aimed at the evaluation of long-term safety and efficacy. Most of the patients $(86 \%)$ continued to receive infliximab for 5 years, and they had good outcomes: only four of 103 patients dropped out of the study due to lack of efficacy. Venetsanopoulou et $\mathrm{al}^{21}$ also investigated infliximab's long-term efficacy, in addition to other parameters, such as tolerability, adverse events, and drug discontinuation. Thirty-five AS patients were enrolled and followed for 4 years. The BASDAI 50 response was $48.6 \%$ after both the third and fourth years, the ASAS 40 was $54.3 \%$ and $48.6 \%$ after the third and fourth years, respectively, and the ASAS 5/6 was $42.9 \%$ after both the third and fourth years. Drug survival was $94.3 \%$ after the first year, 91.4\% after the second year, and 85.7\% and $77.9 \%$ after the third and fourth years, respectively. Extra-articular manifestations were also found to be halted by infliximab.

\section{Extra-articular manifestations}

Approximately $20 \%-30 \%$ of AS patients develop uveitis. ${ }^{5}$ One meta-analysis showed that infliximab significantly reduced the incidence of uveitis compared with placebo $(P=0.005) .{ }^{16} \mathrm{Up}$ to $60 \%$ of AS patients have subclinical gut inflammation, which might later evolve into inflammatory 


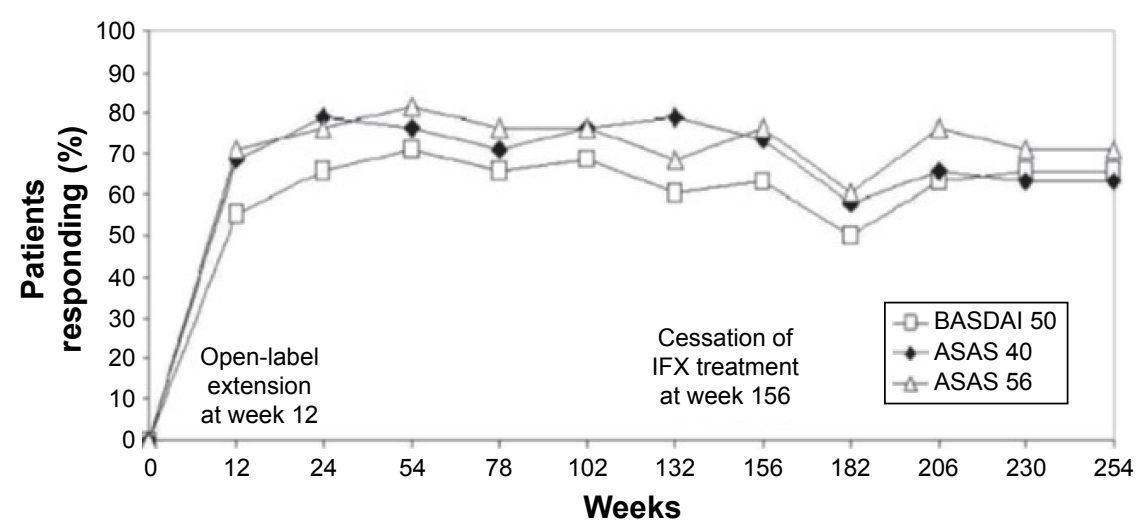

Figure 2 Ankylosing spondylitis: improvement in disease activity.

Notes: Infliximab sustained improvement in disease activity over 5 years. At I 56 weeks, $n=43$ patients; at 254 weeks, $n=38$ patients.

Abbreviations: ASAS, Assessment of Spondyloarthritis International Society; BASDAI, Bath Ankylosing Spondylitis Disease Activity Index; IFX, infliximab.

bowel disease. ${ }^{22}$ Another meta-analysis showed that AS patients treated with infliximab had reduced incidences of flares or new-onset inflammatory bowel disease compared with etanercept $(P=0.001)$ and adalimumab $(P=0.02) .{ }^{23}$ Bone density was also shown to have improved under 24 weeks of infliximab treatment, as had been demonstrated in the ASSERT trial $(P<0.001),{ }^{24}$ although the effect on vertebral fractures still remained to be evaluated. Arends et al's ${ }^{25}$ observational study evaluated the effects of anti-TNF $\alpha$ on bone turnover and bone density in AS patients by comparing bone markers and bone density of treated and untreated patients. After 3 years, 65 of the 111 patients (65\%) were still under anti-TNF $\alpha$ therapy. Significant positive changes in bone metabolism compared to baseline values were noted in the treated patients, including increased alkaline phosphatase (a marker of bone formation), decreased serum collagen telopeptide (a marker of bone resorption), and increased lumbar spine and hip-bone mineral density.

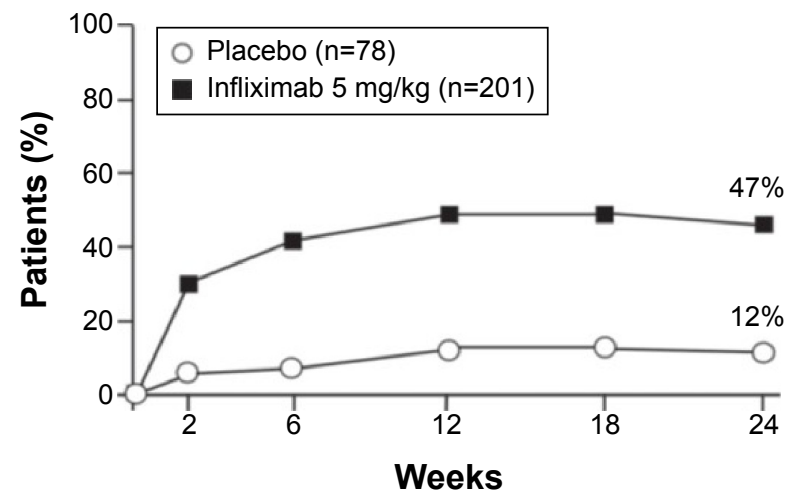

Figure 3 Ankylosing spondylitis: rapid clinical response.

Notes: Infliximab rapidly improved ASAS 40 compared with placebo $(n=279$ patients). $P<0.00$ I from 2 weeks onward.

Abbreviation: ASAS, Assessment of the Spondyloarthritis International Society

\section{Predictors of response}

Others studies have tried to evaluate the predictors of good response to anti-TNF $\alpha$ agents. Arends et $\mathrm{al}^{26}$ evaluated 220 patients with AS who started therapy with infliximab $(n=32)$, etanercept $(n=137)$, or adalimumab $(n=51)$. ASAS 20 scores were $68 \%$ and $63 \%$ at 3 and 6 months, respectively, and ASAS 40 scores were $49 \%$ and $46 \%$ at 6 and 3 months, respectively, while BASDAI 50 was achieved by $49 \%$ and $50 \%$ of the patients at 3 and 6 months, respectively. The percentage of the responders was comparable between the different anti-TNF $\alpha$-agent groups. Baseline predictors of response were younger age, male sex, higher Ankylosing Spondylitis Disease Activity Score, higher erythrocyte sedimentation rate (ESR) level, higher C-reactive protein (CRP) level, presence of peripheral arthritis, higher patient global assessment of disease activity, and lower modified Schober test score. Baseline predictors of discontinuation of TNF $\alpha$-blocking therapy were female sex, absence of peripheral arthritis, higher BASDAI, lower ESR level, and lower CRP level. ${ }^{27}$ Vastesaeger et al also evaluated predictors of response based on the ASSERT and GO-RAISE trials; they evaluated 635 anti-TNF $\alpha$ patients. Algorithmbased prediction models were created, and concluded that age, Bath Ankylosing Spondylitis Functional Index score, enthesitis, CRP, and HLA-B27 genotype were identified as predictors, and they suggested using this model in selecting patients for biologic therapy. ${ }^{28}$ An important question is whether efficacy is maintained despite dose reduction of infliximab and extended infusion interval. Mörck et $\mathrm{al}^{29}$ investigated whether efficacy is maintained after reduction of the infliximab dose from $5 \mathrm{mg} / \mathrm{kg}$ to $3 \mathrm{mg} / \mathrm{kg}$ and if the interval between infusions is prolonged from 6 weeks to 8 weeks in 19 AS HLAB27-positive patients. Those authors 
found that efficacy was maintained, based on BASDAI and inflammatory parameters, despite the extended intervals and dose reduction. Several studies that tried to cease the anti-TNF $\alpha$ agent completely in AS patients and in nonradiographic axial spondylarthritis suggested that relapse is almost inevitable. In one study, 41 of 42 AS patients relapsed after discontinuing infliximab within 1 year, and most of the patients gained remission after reintroduction of the drug. ${ }^{30}$ Similar results were demonstrated in 24 AS patients treated with etanercept. ${ }^{31}$

What are the reasons for good initial response and for failure to respond or develop infusion reactions after a certain period? One of the possible explanations is immunogenicity. Plasencia et al $^{32}$ evaluated the relevance of antibodies to infliximab in 94 patients with spondylarthritis who were undergoing infliximab treatment. Antidrug antibody formation was found to be associated with poor clinical response, the appearance of infusion reactions, and discontinuation of treatment. Kneepkens et $\mathrm{al}^{33}$ evaluated the same question using adalimumab in AS patients, and found that adalimumab levels were related to clinical response (as measured with Ankylosing Spondylitis Disease Activity Score) and influenced by antidrug antibodies.

\section{Radiological response}

Axial inflammatory activity of AS demonstrated in magnetic resonance imaging has been well documented to respond to anti-TNF $\alpha$ therapy. ${ }^{21,34}$ The answer to the more interesting question whether structural damage can be halted due to suppressed inflammation is still pending. The difficulty in answering this question comes both from slow radiological progression and inability to conduct long-run placebo-controlled trials, and thus most of the data come from observational trials and comparisons to historical cohorts.

Louie et al showed that studies with a relative short time frame of up to 2 years of treatment mostly failed to show a positive effect of anti-TNF $\alpha$ therapy on radiological progression, while emerging longer observational studies are starting to demonstrate markers of halted progression. ${ }^{35}$ A study by van der Heijde et $\mathrm{al}^{36}$ that was done using the ASSERT trial data specifically examined the effect of infliximab on radiographic progression in AS patients compared to the OASIS data. AS patients who received infliximab from baseline through week 96 did not show a significant difference in the inhibition of structural damage progression at year 2, as assessed by the modified Stoke Ankylosing Spondylitis Spine Score (mSASSS) system, when compared with radiographic data from the OASIS cohort historical control.
On the other hand, Baraliakos et $\mathrm{al}^{37}$ evaluated radiographic progression using conventional radiographs in AS patients treated with infliximab during a period of 4 years. The control group was the historical OASIS cohort. Although radiographic progression was demonstrated after 2 and 4 years of infliximab therapy in the AS patients' (1.6 \pm 2.6$)$ mSASSS, it was less than the progression documented for the OASIS cohort (4.4), suggesting that infliximab may decelerate the progression of structural changes. Another retrospective study by Baraliakos et $\mathrm{al}^{38}$ evaluated the radiographic progression in AS patients treated with infliximab over 8 years compared to historical controls who had never been treated with TNF $\alpha$ blockers. Lateral cervical and lumbar radiographs were graded by blinded radiologists and scored by the mSASSS. The results demonstrated similar mSASSSs between the groups at 4 years, but showed a larger increase in the untreated group after 8 years (mean mSASSS was 0.9 per year in the treated group vs 1.5 in the untreated group). Less syndesmophyte formation was noted as well in the treated patients after 8 years, which argues against the TNF-brake hypothesis. Haroon et $\mathrm{al}^{39}$ also investigated the effect of antiTNF $\alpha$ agents on progressive spinal damage by conducting an observational study of 334 AS patients. Radiographic severity was assessed by the mSASSS. Patients with at least two sets of radiographs taken at a minimum of 1.5 years apart were included. TNF $\alpha$-inhibitor treatment was associated with a $50 \%$ reduction in the odds of progression, with an odds ratio of 0.52 (95\% confidence interval [CI] $0.30-0.88$, $P=0.02)$. Patients with a delay $>10$ years in starting therapy were more likely to experience progression compared to those who started earlier.

\section{Safety}

Safety considerations regarding therapy with anti-TNF $\alpha$ blockers are well characterized, due to over 15 years of experience and in great part due to national registries of thousands of patients receiving biological therapies for different indications. There are no major safety differences between the different anti-TNF $\alpha$ agents and indications, such as rheumatoid arthritis (RA), AS, and psoriatic arthritis. Therefore, this review covers safety issues regarding infliximab for all the aforementioned diseases. Patients receiving anti-TNF $\alpha$ agents often concomitantly use other agents, such as corticosteroids, azathioprine, mercaptopurine, and methotrexate, which may further contribute to side effects, such as infections. DMARDs and corticosteroid therapy are not part of the treatment guidelines of AS, unlike other inflammatory disease, such as RA and inflammatory 
bowel disease, and hence no assumption can be made about reduced adverse effects of AS patients treated with TNF $\alpha$ inhibitors compared to other diseases. There have been no publications of well-designed clinical studies to resolve this issue.

Serious adverse events with infliximab and other antiTNF $\alpha$ agents include increased susceptibility for infectious diseases, such as tuberculosis (TB), invasive fungal infections, reactivation of hepatitis B virus, worsening of hepatitis $\mathrm{C}$, and more. Allergic reactions ranging from mild infusion reaction to anaphylaxis have been documented, as have been malignancies, such as lymphoma and nonmelanoma skin cancers, as well as worsening of congestive heart failure, autoantibody formation, such as antinuclear antibody and anti-double-strand DNA antibody, neurological disorders, such as optic neuritis and seizures, and demyelinating disorders. In a recent report, Tong et al reported about adverse events of anti-TNF $\alpha$ therapy in 402 Han Chinese with AS. ${ }^{40}$ Short- and long-term adverse events were evaluated regarding treatment with infliximab and recombinant human TNF $\alpha$-receptor II:IgG Fc (rhTNFR-Fc). With regard to shortterm adverse events, no significant differences between the two drugs were noted. Long-term adverse events occurred in $11 \%$ in the rhTNFR-Fc group vs $23.3 \%$ in the infliximab group ( $P=0.0013)$. Most long-term events were infectious disease, especially pneumonia and urinary tract infection, and the only significant difference regarding infectious disease between these groups was higher urinary tract infections in the infliximab arm. High baseline CRP and ESR was a predictor of long-term adverse events, and surprisingly elevated CRP and ESR were protective against short-term adverse events. Table 1 summarizes the important adverse events of infliximab.

\section{Infections}

Two RA registry-based studies assessed the safety profiles of biologic agents in comparison to synthetic DMARDs, and found no major differences in infectious adverse events between the two arms. The first assessment ${ }^{41}$ was based on the RADIUS registry, which evaluated 10,000 patients with RA. There were no unexpected safety signals and no trends of reasons for concern compared with the data that were recorded during earlier trials and in the early days of TNF-inhibiting therapies. Additionally, the incidences of serious adverse events and serious infections of anti-TNF $\alpha$ agents were comparable with those of methotrexate. Similar conclusions were drawn from the second assessment, which was an observational cohort of the Consortium of Rheumatology Researchers of North America registry, which included 18,305 RA patients. ${ }^{42}$ There was no significant increase in adjusted risk for overall infections associated with anti-TNF $\alpha$ therapy compared with methotrexate, and infection-related safety profiles of the various biologic agents appeared to be similar.

Dixon et $\mathrm{al}^{43}$ evaluated the rates of serious infection, including site-specific and bacterial intracellular infection, in RA patients receiving anti-TNF $\alpha$ therapy. That national prospective observational study used the British Society for Rheumatology Biologics Register, which included 7,664 anti-TNF $\alpha$-treated and 1,354 DMARD-treated patients with severe RA. All serious infections that were stratified by site and organism were included in the analysis. The crude rates of serious infections were found to be similar among TNF inhibitors: at approximately 50 events per 1,000 person-years for etanercept, infliximab, and adalimumab. The incidence-rate ratio, adjusted for baseline risk, for the TNF $\alpha$-inhibitor cohort compared with the DMARD cohort was 1.03 (95\% CI 0.68-1.57), suggesting similar risk levels between the two arms. However, the types of serious infections were different between the groups, with 19 serious bacterial intracellular infections (ten Mycobacterium TB, two Legionella pneumophila, three Listeria monocytogenes, one Mycobacterium fortuitum, and three Salmonella) occurring exclusively in patients in the TNFoinhibitor cohort.

After adjustment for baseline risk, anti-TNF $\alpha$ therapy was not associated with an increased risk of overall serious infections compared with DMARD treatment in patients with active RA. However, the frequency of serious skin and softtissue infections was higher in anti-TNF $\alpha$-treated patients,

Table I Main side effects of infliximab in patients with ankylosing spondylitis

\begin{tabular}{lll}
\hline Infections & Malignancy & Autoimmune \\
\hline Bacterial & Nonmelanoma skin cancer & Demyelinating disease \\
Tuberculosis & Lymphoma & Lupus-like \\
Fungal infections & & Alopecia areata \\
HBV, HCV reactivation & & Psoriasis \\
Varicella zoster & &
\end{tabular}

Abbreviations: $\mathrm{HBV}$, hepatitis $B$ virus; $\mathrm{HCV}$, hepatitis $\mathrm{C}$ virus. 
with an adjusted relative risk of 4.28 (95\% CI 1.06-17.17). Additional data on Mycobacterium TB infection came from the French RATIO registry, which showed an increased risk of infection in patients treated with infliximab and other anti-TNF therapies, although this risk might be lower with etanercept. ${ }^{44}$ Of note, none of those cases received TB prophylaxis. A large randomized, placebo-controlled trial assessed the risk of serious infections after 22 weeks of treatment with infliximab $3 \mathrm{mg} / \mathrm{kg}$ or $10 \mathrm{mg} / \mathrm{kg}$ vs placebo in active RA patients receiving methotrexate. ${ }^{45}$ There was a higher incidence of serious infections, with a relative risk of 3.1 (95\% CI 1.2-7.9, $P=0.013$ ) in the unapproved higherdosage arm compared to the placebo group, but not to the approved dosage group.

A prospective cohort study of the German RA registry RABBIT compared the rates of infections in patients treated with the biologic agents infliximab, etanercept, and anakinra with rates of infections in patients receiving conventional DMARDs. After adjustment for differences in the casepatient mix, the relative risks of serious adverse events were 2.2 (95\% CI 0.9-5.4) for patients receiving etanercept and 2.1 (95\% CI 0.8-5.5) for patients receiving infliximab compared with controls. ${ }^{46}$ Other research also suggests an increased risk of herpes zoster infection in patients treated with TNF antagonists, except for etanercept. ${ }^{47}$ Of note, most infections reported in clinical trials of TNF $\alpha$ inhibitors have been minor, and were treated with either outpatient antibiotic therapy and/or temporary withdrawal of the drug. ${ }^{48}$

\section{Malignancy}

The use of anti-TNF $\alpha$ agents in malignancy has gained some attention, due to their mechanism of opposing tumor cytokines. However, although the first described action of TNF was to oppose tumor cells, it has also protumor action, ${ }^{49}$ thus making this issue more complicated and leading to inconclusive results in different studies on this important aspect.

Moulis et $\mathrm{al}^{50}$ conducted a meta-analysis of 33 doubleblind randomized controlled trials in adult RA patients, and found no excessive risk of malignancy with any of five anti-TNF $\alpha$ agents during up to 2 years of treatment. However, there was a tendency toward an increased rate of nonmelanoma skin cancer in different reports. ${ }^{51}$ Two other meta-analyses - one on etanercept alone ${ }^{52}$ and another on adalimumab, infliximab, and etanercept that included more than 26,000 patients $^{53}$ - did not demonstrate a significant increase in the risk of malignancy. Other research has suggested an increased risk of lymphoma in anti-TNF $\alpha$-treated patients, but those results were complicated by the association of RA and increased lymphoma risk. ${ }^{54}$ Currently, no definite conclusion has been reached regarding lymphoma risk with TNF $\alpha$ inhibitors, and postmarketing pharmacovigilance continues to track the incidence of lymphoma among individuals who are treated with them.

\section{Autoimmune disorders}

Anti-TNF $\alpha$ agents are not effective for the treatment of MS, and many small studies and series described demyelination following the use of TNF inhibitors. ${ }^{55}$ Lupus-like symptoms and autoantibodies have been reported with each of the TNF inhibitors, apparently with decreased prevalence with etanercept compared to monoclonal antibodies. ${ }^{56}$ Alopecia areata was recently reported to be associated with treatment with infliximab, adalimumab, etanercept, and certolizumab. ${ }^{57}$ Finally, an increased risk of psoriasis was reported in a retrospective cohort study of RA patients treated with TNF inhibitors. ${ }^{58}$ Infusion reactions ranged from mild infusion reaction (nausea, headache, flushing) to anaphylaxis, which is more common in infliximab due to its chimeric structure. Overall, infusion reactions occur in approximately $4 \%$ of patients compared to $1.6 \%$ for placebo, and most of the reactions are mild to moderate.

\section{Conclusion}

The management of AS and other inflammatory diseases has changed dramatically since the introduction of infliximab and other anti-TNF $\alpha$ agents. After more than 15 years of experience, the efficacy and safety profile of infliximab for the treatment of AS is now well established. Infliximab is an efficient therapy for the treatment of the different aspects of active AS, including axial, articular, and extra-articular manifestations. The main concern with infliximab and other biological agents is the inhibition of the immune system and the subsequent increased susceptibility for bacterial, viral, and fungal infections. There is probably a mild increased risk for general infections and opportunistic agents as well, with TB being the main concern. TB screening should be done before commencing therapy that consists of any one of the anti-TNF $\alpha$ agents, and anti-TB therapy should be given in cases of latent TB. Screening for hepatitis B virus and hepatitis $\mathrm{C}$ virus should be done as well, since activation of latent hepatitis $B$ virus infection and deterioration of hepatitis $\mathrm{C}$ virus have been documented as well. Other serious adverse effects, such as malignancy, autoimmunity, and congestive heart-failure exacerbation, have been described as well, but there are no specific guidelines for dealing with 
these important issues, and their role in decision making still needs to be better defined.

\section{Disclosure}

The authors report no conflicts of interest in this work.

\section{References}

1. Gran J, Husby G. The epidemiology of ankylosing spondylitis. Semin Arthritis Rheum. 1993;22:319-334.

2. Braun J, Sieper J. The sacroiliac joint in the spondyloarthropathies. Curr Opin Rheumatol. 1996;8:275-287.

3. Lee J, Jun J, Jung S, et al. Higher prevalence of peripheral arthritis among ankylosing spondylitis patients. J Korean Med Sci. 2002;17: 669-673.

4. Peters M, van der Horst-Bruinsma I, Dijkmans B, Nurmohamed M. Cardiovascular risk profile of patients with spondylarthropathies, particularly ankylosing spondylitis and psoriatic arthritis. Semin Arthritis Rheum. 2004;34:585-592.

5. Rosenbaum J. Acute anterior uveitis and spondyloarthropathies. Rheum Dis Clin North Am. 1992;18:143-151.

6. Baeten D, De Keyser F, Mielants H, Veys E. Ankylosing spondylitis and bowel disease. Best Pract Res Clin Rheumatol. 2002;16:537-549.

7. Smolen J, Braun J, Dougados M, et al. Treating spondyloarthritis, including ankylosing spondylitis and psoriatic arthritis, to target: recommendations of an international task force. Ann Rheum Dis. 2014;73 $6-16$.

8. Doran M, Brophy S, MacKay K, et al. Predictors of long-term outcome in ankylosing spondylitis. J Rheumatol. 2003;30:316-320.

9. Song I, Poddubnyy D, Rudwaleit M, Sieper J. Benefits and risks of ankylosing spondylitis treatment with nonsteroidal antiinflammatory drugs. Arthritis Rheum. 2008;58:929-938.

10. Chen J, Liu C, Lin J. Methotrexate for ankylosing spondylitis. Cochrane Database Syst Rev. 2006:CD004524.

11. Clegg D, Reda D, Abdellatif M. Comparison of sulfasalazine and placebo for the treatment of axial and peripheral articular manifestations of the seronegative spondylarthropathies: a Department of Veterans Affairs cooperative study. Arthritis Rheum. 1999;42:2325-2329.

12. Haibel H, Fendler C, Listing J, Callhoff J, Braun J, Sieper J. Efficacy of oral prednisolone in active ankylosing spondylitis: results of a doubleblind, randomized, placebo-controlled short-term trial. Ann Rheum Dis. 2014;73:243-246.

13. Brandt J, Haibel H, Cornely D, et al. Successful treatment of active ankylosing spondylitis with the anti-tumor necrosis factor $\alpha$ monoclonal antibody infliximab. Arthritis Rheum. 2000;43:1346-1352.

14. Braun J, Brandt J, Listing J, et al. Treatment of active ankylosing spondylitis with infliximab: a randomised controlled multicentre trial. Lancet. 2002;359:1187-1193.

15. Grainger R, Harrison AA. Infliximab in the treatment of ankylosing spondylitis. Biologics. 2007;1:163-171.

16. Braun J, Baraliakos X, Listing J, Sieper J. Decreased incidence of anterior uveitis in patients with ankylosing spondylitis treated with the anti-tumor necrosis factor agents infliximab and etanercept. Arthritis Rheum. 2005;52:2447-2451.

17. Braun J, Brandt J, Listing A, et al. Two year maintenance of efficacy and safety of infliximab in the treatment of ankylosing spondylitis. Ann Rheum Dis. 2005;64:229-234.

18. Braun J, Baraliakos X, Listing J, et al. Persistent clinical efficacy and safety of anti-tumour necrosis factor- $\alpha$ therapy with infliximab in patients with ankylosing spondylitis over 5 years: evidence for different types of response. Ann Rheum Dis. 2008;67:340-345.

19. van der Heijde D, Dijkmans B, Geusens P, et al. Efficacy and safety of infliximab in patients with ankylosing spondylitis: results of a randomized, placebo-controlled trial (ASSERT). Arthritis Rheum. 2005;52:582-591.
20. Heldmann F, Brandt J, van der Horst-Bruinsma IE, et al. The European Ankylosing Spondylitis Infliximab Cohort (EASIC): a European multicentre study of long term outcomes in patients with ankylosing spondylitis treated with infliximab. Clin Exp Rheumatol. 2011;29: 672-680.

21. Venetsanopoulou AI, Voulgari PV, Alamanos Y, Papadopoulos CG, Markatseli TE, Drosos AA. Persistent clinical response of infliximab treatment, over a 4-year period in ankylosing spondylitis. Rheumatol Int. 2007;27:935-939.

22. Mielants H, Veys E, Cuvelier C, de Vos M. Course of gut inflammation in spondylarthropathies and therapeutic consequences. Baillieres Clin Rheumatol. 1996;10:147-164.

23. Braun J, Baraliakos X, Listing J, et al. Differences in the incidence of flares or new onset of inflammatory bowel diseases in patients with ankylosing spondylitis exposed to therapy with anti-tumor necrosis factor $\alpha$ agents. Arthritis Rheum. 2007;57:639-647.

24. Visvanathan S, van der Heijde D, Deodhar A, et al. Effects of infliximab on markers of inflammation and bone turnover and associations with bone mineral density in patients with ankylosing spondylitis. Ann Rheum Dis. 2009;68:175-182.

25. Arends S, Spoorenberg A, Houtman P, et al. The effect of three years of TNF $\alpha$ blocking therapy on markers of bone turnover and their predictive value for treatment discontinuation in patients with ankylosing spondylitis: a prospective longitudinal observational cohort study. Arthritis Res Ther. 2012;14:R98.

26. Arends S, van der Veer E, Kallenberg CG, Brouwer E, Spoorenberg A. Baseline predictors of response to TNF- $\alpha$ blocking therapy in ankylosing spondylitis. Curr Opin Rheumatol. 2012;24:290-298.

27. Arends S, Brouwer E, van der Veer E, et al. Baseline predictors of response and discontinuation of tumor necrosis factor-alpha blocking therapy in ankylosing spondylitis: a prospective longitudinal observational cohort study. Arthritis Res Ther. 2011;13:R94.

28. Vastesaeger N, van der Heijde D, Inman RD, et al. Predicting the outcome of ankylosing spondylitis therapy. Ann Rheum Dis. 2011;70: 973-981.

29. Mörck B, Pullerits R, Geijer M, Bremell T, Forsblad-d'Elia H. Infliximab dose reduction sustains the clinical treatment effect in active HLAB27 positive ankylosing spondylitis: a two-year pilot study. Mediators Inflamm. 2013;2013:289845.

30. Baraliakos X, Listing J, Brandt J, et al. Clinical response to discontinuation of anti-TNF therapy in patients with ankylosing spondylitis after 3 years of continuous treatment with infliximab. Arthritis Res Ther. 2005; 7:R439-R444.

31. Brandt J, Listing J, Haibel H, et al. Long-term efficacy and safety of etanercept after readministration in patients with active ankylosing spondylitis. Rheumatology (Oxford). 2005;44:342-348.

32. Plasencia C, Pascual-Salcedo D, Nuño L, et al. Influence of immunogenicity on the efficacy of long-term treatment of spondyloarthritis with infliximab. Ann Rheum Dis. 2012;71:1955-1960.

33. Kneepkens E, Wei J, Nurmohamed M, Yeo K, et al. Extended report: immunogenicity, adalimumab levels and clinical response in ankylosing spondylitis patients during 24 weeks of follow-up. Ann Rheum Dis. 2015;74:396-401.

34. Barkham N, Keen H, Coates L, et al. Clinical and imaging efficacy of infliximab in HLA-B27-positive patients with magnetic resonance imagingdetermined early sacroiliitis. Arthritis Rheum. 2009;60:946-954.

35. Louie GH, Ward MM. Measurement and treatment of radiographic progression in ankylosing spondylitis: lessons learned from observational studies and clinical trials. Curr Opin Rheumatol. 2014;26: $145-150$.

36. van der Heijde D, Landewé R, Baraliakos X, et al. Radiographic findings following two years of infliximab therapy in patients with ankylosing spondylitis. Arthritis Rheum. 2008;58:3063-3070.

37. Baraliakos X, Listing J, Brandt J, et al. Radiographic progression in patients with ankylosing spondylitis after 4 yrs of treatment with the anti-TNF- $\alpha$ antibody infliximab. Rheumatology (Oxford). 2007;46:1450-1453. 
38. Baraliakos X, Haibel H, Listing J, Sieper J, Braun J. Continuous longterm anti-TNF therapy does not lead to an increase in the rate of new bone formation over 8 years in patients with ankylosing spondylitis. Ann Rheum Dis. 2014;73:710-715.

39. Haroon N, Inman R, Learch T, et al. The impact of tumor necrosis factor $\alpha$ inhibitors on radiographic progression in ankylosing spondylitis. Arthritis Rheum. 2013;65:2645-2454.

40. Tong Q, Cai Q, de Mooij T, el al. Adverse events of anti-tumor necrosis factor $\alpha$ therapy in ankylosing spondylitis. PLoS One. 2015;10: $\mathrm{e} 0119897$.

41. Gibofsky A, Palmer W, Keystone E, et al. Safety profiles of diseasemodifying anti-rheumatic drugs and biologics in patients with rheumatoid arthritis: observations from the RADIUS registry. Arthritis Rheum. 2009;60 Suppl 10:1593.

42. Curtis J, Chen L, Cush J, et al. The risk for hospitalized and outpatient infections related to anti-TNF therapy and newer biologics. Arthritis Rheum. 2009;60 Suppl 10:2059.

43. Dixon WG, Watson K, Lunt M, Hyrich KL, Silman AJ, Symmons DP Rates of serious infection, including site-specific and bacterial intracellular infection, in rheumatoid arthritis patients receiving anti-tumor necrosis factor therapy: results from the British Society for Rheumatology Biologics Register. Arthritis Rheum. 2006;54:2368-2376.

44. Tubach F, Salmon D, Ravaud P, et al. Risk of tuberculosis is higher with anti-tumor necrosis factor monoclonal antibody therapy than with soluble tumor necrosis factor receptor therapy: the three-year prospective French Research Axed on Tolerance of Biotherapies registry. Arthritis Rheum. 2009;60:1884-1894.

45. Westhovens R, Yocum D, Han J, et al. The safety of infliximab, compared with background treatments, among patients with rheumatoid arthritis and various comorbidities: a large, randomized, placebocontrolled trial. Arthritis Rheum. 2006;54:1075-1086.

46. Listing J, Strangfeld A, Kary S, et al. Infections in patients with rheumatoid arthritis treated with biologic agents. Arthritis Rheum. 2005;52: 3403-3412.

47. Strangfeld A, Listing J, Herzer P. Risk of herpes zoster in patients with rheumatoid arthritis treated with anti-TNF- $\alpha$ agents. JAMA. 2009;301: 737-744.

48. Keystone E. Advances in targeted therapy: safety of biological agents. Ann Rheum Dis. 2003;62 Suppl 2:ii34-ii36.
49. Balkwill F, Mantovani A. Cancer and inflammation: implications for pharmacology and therapeutics. Clin Pharmacol Ther. 2010;87: 401-406.

50. Moulis G, Sommet A, Béné J. Cancer risk of anti-TNF- $\alpha$ at recommended doses in adult rheumatoid arthritis: a meta-analysis with intention to treat and per protocol analyses. PLOS One. 2012;7:e48991.

51. Mariette X, Matucci-Cerinic M, Pavelka K. Malignancies associated with tumor necrosis factor inhibitors in registries and prospective observational studies: a systematic review and meta-analysis. Ann Rheum Dis. 2011;70:1895-1904.

52. Baecklund E, Ekbom A, Sparén P, Feltelius N, Klareskog L. Disease activity and risk of lymphoma in patients with rheumatoid arthritis: nested case-control study. BMJ. 1998;317:180-181.

53. Askling J, Fahrbach K, Nordstrom B, Ross S, Schmid CH, Symmons D. Cancer risk with tumor necrosis factor alpha (TNF) inhibitors: metaanalysis of randomized controlled trials of adalimumab, etanercept, and infliximab using patient level data. Pharmacoepidemiol Drug Saf. 2011;20:119-130.

54. Baecklund E, Iliadou A, Askling J, et al. Association of chronic inflammation, not its treatment, with increased lymphoma risk in rheumatoid arthritis. Arthritis Rheum. 2006;54:692-701.

55. Magnano M, Robinson W, Genovese M. Demyelination and inhibition of tumor necrosis factor (TNF). Clin Exp Rheumatol. 2004;22: S134-S140.

56. Moulis G, Sommet A, Lapeyre-Mestre M, Montastruc J. Is the risk of tumour necrosis factor inhibitor-induced lupus or lupus-like syndrome the same with monoclonal antibodies and soluble receptor? A case/noncase study in a nationwide pharmacovigilance database. Rheumatology (Oxford). 2014;53:1864-1871.

57. Béné J, Moulis G, Auffret M, Fessier C, Lefevre G, Gautier S. Tumor necrosis factor antagonists and alopecia: a case/non case in a nationwide pharmacovigilance database. Arthritis Rheum. 2012;64:S788.

58. Harrison M, Dixon W, Watson K. Rates of new-onset psoriasis in patients with rheumatoid arthritis receiving anti-tumour necrosis factor $\alpha$ therapy: results from the British Society for Rheumatology Biologics Register. Ann Rheum Dis. 2009;68:209-215.
Therapeutics and Clinical Risk Management

\section{Publish your work in this journal}

Therapeutics and Clinical Risk Management is an international, peerreviewed journal of clinical therapeutics and risk management, focusing on concise rapid reporting of clinical studies in all therapeutic areas, outcomes, safety, and programs for the effective, safe, and sustained use of medicines. This journal is indexed on PubMed Central, CAS,
Dovepress

EMBase, Scopus and the Elsevier Bibliographic databases. The manuscript management system is completely online and includes a very quick and fair peer-review system, which is all easy to use. Visit http://www.dovepress.com/testimonials.php to read real quotes from published authors. 